\title{
DETERMINING ARMOURED SCALE DISTRIBUTION WITHIN KIWIFRUIT BLOCKS
}

\author{
R.H. BLANK ${ }^{1}$, G.S.C. GILL ${ }^{1}$ and B.W. DOW ${ }^{2}$ \\ HortResearch, ${ }^{1}$ Whangarei Research Centre, Private Bag 9003 Whangarei \\ ${ }^{2}$ Ruakura Research Centre, Private Bag 3123 Hamilton
}

\begin{abstract}
Scale leaf infestations from kiwifruit rows were used to determine scale distributions in three adjacent blocks of kiwifruit at two orchards. Analysis using regression models showed that the combined data for six sampling times from December to May can be used to describe scale distributions across the rows. These were best described using a linear relationship for five blocks and a quadratic for one block. Scale distribution patterns were found to hold throughout the season for five blocks. Scale leaf infestation data collected using the Kiwigreen sampling procedure were inadequate for describing inter-row scale distribution.
\end{abstract}

Keywords: Kiwifruit, armoured scale insects, scale distribution, shelter

\section{INTRODUCTION}

Armoured scale insects (Hemiptera: Diaspididae) are important quarantine pests of kiwifruit (Actinidia deliciosa) grown in New Zealand for export (Steven 1990). Greedy scale (Hemiberlesia rapax (Comstock)), latania scale (Hemiberlesia lataniae(Signoret)), and oleander scale (Aspidiotus nerii Bouché) are the most common species found on kiwifruit (Berry et al. 1989; Lo and Blank 1989).

The distribution of armoured scale insects (scale) within kiwifruit orchards was of little interest when the industry was reliant on a calendar based, prophylactic spray programme to control pests. However, with the adoption of the Kiwigreen programme, the industry is committed to targeting sprays only against known pest infestations within approximately 100 days of harvest. In the case of scale, this is achieved by monitoring levels of leaf infestations and applying mineral oil sprays when a critical level is exceeded. We estimate that pest monitoring cost the industry over \$5 million in the 1997 season with approximately half of this cost due to scale. It is therefore imperative that the pest monitoring procedures are meaningful, accurate and cost effective. An essential prerequisite to developing pest sampling programmes is an understanding of the distribution of the pest (Southwood 1978). Scale distribution within kiwifruit orchards is poorly known. The objective of this study was to develop procedures for quantifying scale distribution within kiwifruit blocks.

\section{Sites}

\section{METHODS}

Two commercial kiwifruit orchards with a high risk of scale infestation were selected for this investigation. Site A comprised three adjacent blocks of kiwifruit grown on pergola structures with rows (five $m$ apart) aligned parallel and to the west side of taraire trees. Block 1 started 50 metres from the taraire, with Blocks 2, and 3 progressively further away. All blocks had willow trees,Salixmatsudanax Salix alba hybrid 1002 (12 $\mathrm{m}$ high), as shelter-belts on both sides and parallel to the rows.

At Site B, scale infestations were monitored in from three adjacent blocks of kiwifruit grown on a T-bar structure and with rows (5 m apart) aligned north-south and parallel to taraire trees. These trees provided a major source of scale infestation and formed a natural shelter-belt along the west side of Block 1. Bamboo shelter,Bambusa oldhami, ( $10 \mathrm{~m}$ high) ran north-south between the blocks. Block 3 was the greatest distance from the taraire trees. 


\section{Leaf sampling}

Kiwifruit leaves were sampled on six occasions from December 1995 until May 1996 at both sites. Equal numbers of leaves were picked at regular intervals along every row, with leaves from the two ends and middle regions bagged separately. A total of 378 or 360 leaves (Sites A and B respectively) was sampled from each block on each occasion. Leaves were assessed under a microscope in the laboratory for the presence of live and dead scale.

Leaf sampling data from the Kiwigreen programme were also obtained for Site B from the Pest Monitoring Centre. Two leaves per bay were sampled from the outside rows in each block and then one leaf per bay from every second internal row to provide 270 (Block 1), 170 (Block 2) and 203 (Block 3) leaves on each of three occasions in 1996. Kiwigreen data for Site A had not been recorded on a row basis and could not be analysed.

\section{Analysis}

An ANOVA was used to determine if there were statistically significant differences in levels of leaf infestation between the two ends and the middle position of all the rows within each block averaged over all sampling occasions. Scale data from all the three positions in the row were combined for inter-row comparisons.

Regression analysis compared scale leaf infestation levels with distance across rows using all the different sampling times. Comparisons were made between different models with parallel lines or parallel quadratics for each sampling time, and different single lines or quadratics for combined means. Linear and quadratic regression analyses of the combined means were also performed and for clarity, are presented as summaries rather than using the more complex regression models with parallel lines. The results of regression analyses are presented as percentage data, rather than the more correct generalised linear model using logistic link and binomial error distributions, as both showed similar trends.

\section{Position within the row}

\section{RESULTS}

Scale infestations were not significantly different between positions within the rows at Site A Blocks 1 and 2 and Site B Block 3. At Site A, the northern end of rows in Block 3 had significantly $(\mathrm{P}<0.05)$ lower levels of total (live plus dead) scale infestations $(8 \%)$ compared to the middle (16\%) and southern end (15\%) averaged over all sampling times. At Site B the southern ends of rows in Block 1 and 2 had significantly $(\mathrm{P}<0.01)$ lower scale infestations $(27,21 \%$ respectively) compared to the middle $(50,37 \%)$ and northern ends $(57,35 \%)$. All rows were sampled to give equal weight to positions along each row. This ensured that differences in scale infestations in different positions did not influence scale distribution across rows in the analysis. To simplify interpretation, data from all three positions within rows for inter-row comparisons have been pooled.

\section{Distribution across rows - testing regression models}

Scale leaf infestation levels at different sampling times gave broadly similar distribution patterns across kiwifruit blocks (example in Fig. 1). Preliminary analysis of individual sampling times yielded a high proportion of significant regressions but also several regressions that were not significant. Difficulties in the handling and interpretation of the data were overcome by testing the combined data for all sampling times in a series of regression models.

The parallel lines for different sampling times were significant for five blocks. In the example shown for Site A Block 1, the regression model that best described the scale distribution was one of parallel lines with the same slope and different intercepts (Fig. 1). Site B, Block 2 did not exhibit any consistent relationship throughout the season, although a quadratic relationship was almost significant $(\mathrm{P}=0.061)$. There was no significant improvement in fitting lines with different slopes or different quadratics in all blocks, so there was no evidence of different relationships at different sampling times.

\section{Distribution across rows - regressions using combined means}

Regressions using mean scale infestations combined over different sampling occasions 


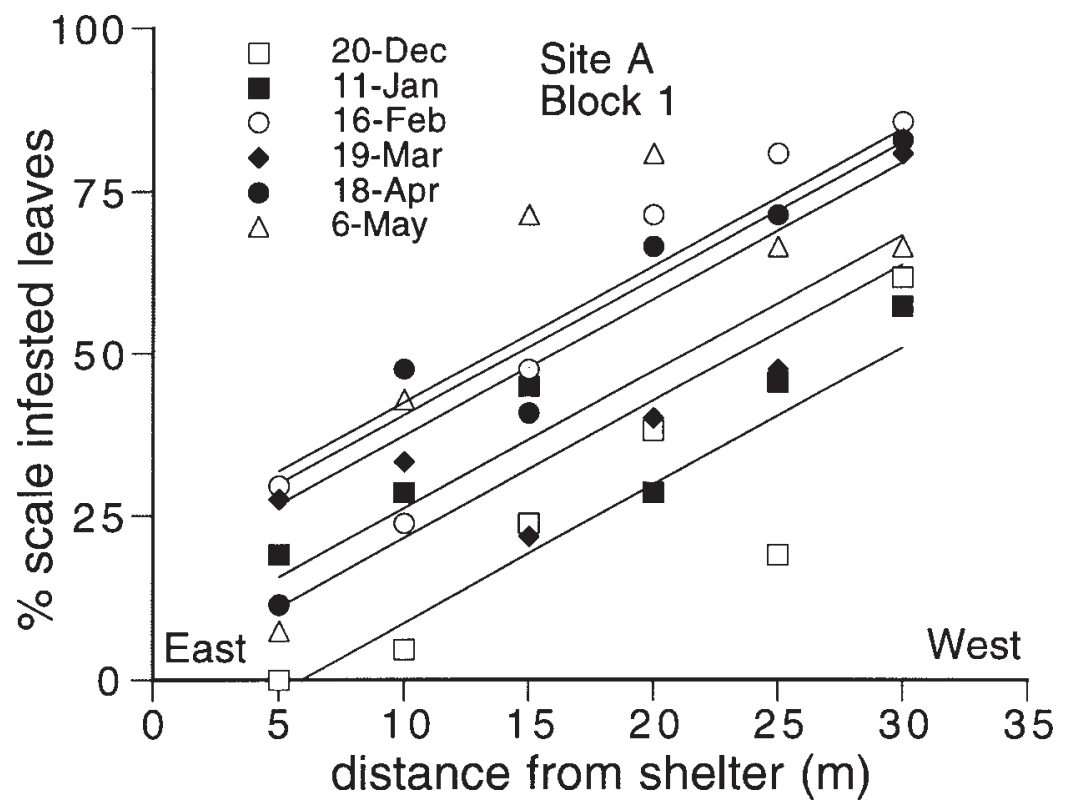

FIGURE 1: Total (live plus dead) scale leaf infestations across kiwifruit rows spaced at $5 \mathrm{~m}$ intervals for six sampling times at Site $\mathrm{A}$, Block 1 . The regression model that gave the best fit was parallel lines with the same slopes but different intercepts.

gave significant linear relationships, except for Site B Block 2 where a quadratic relationship ( $\mathrm{P}=0.056)$ appeared to exist (Fig. 2). Regressions were similar using total (live plus dead) or live scale with no difference in slopes.

At Site A, scale infestation increased linearly by $10 \%$ per row in Blocks 1 and 3 , moving westward and away from taraire trees located about $50 \mathrm{~m}$ to the East of Block 1 (Fig. 2). In contrast, scale infestations declined linearly by $8 \%$ per row in Block 2.

At Site B, scale infestations were highest on kiwifruit rows adjacent to taraire trees and declined linearly by $4 \%$ per row eastwards across Block 1 . In Block 2 , scale numbers were highest in rows near both bamboo shelter-belts and declined towards the middle of the block. In Block 3 scale declined linearly by $2 \%$ per row westwards and away from the taraire trees.

Kiwigreen

Regressions derived from total scale infestation data collected using the Kiwigreen sampling procedure at Site $B$, were not significant $(\mathrm{P}=0.060,0.166,0.077$ for Blocks $1,2,3$ respectively).

\section{DISCUSSION}

The procedure of combining scale leaf infestation data from a number of sampling occasions was useful for describing scale distribution across rows in kiwifruit blocks. Using the data from all sampling times established regression relationships by increasing sample size that was sometimes inadequate for individual sampling times. In all kiwifruit blocks investigated, there was no evidence to suggest that scale distribution changed during the season.

This persistence throughout the season suggests that scale distribution patterns are influenced by the local environment. Earlier studies showed the importance of alternative 


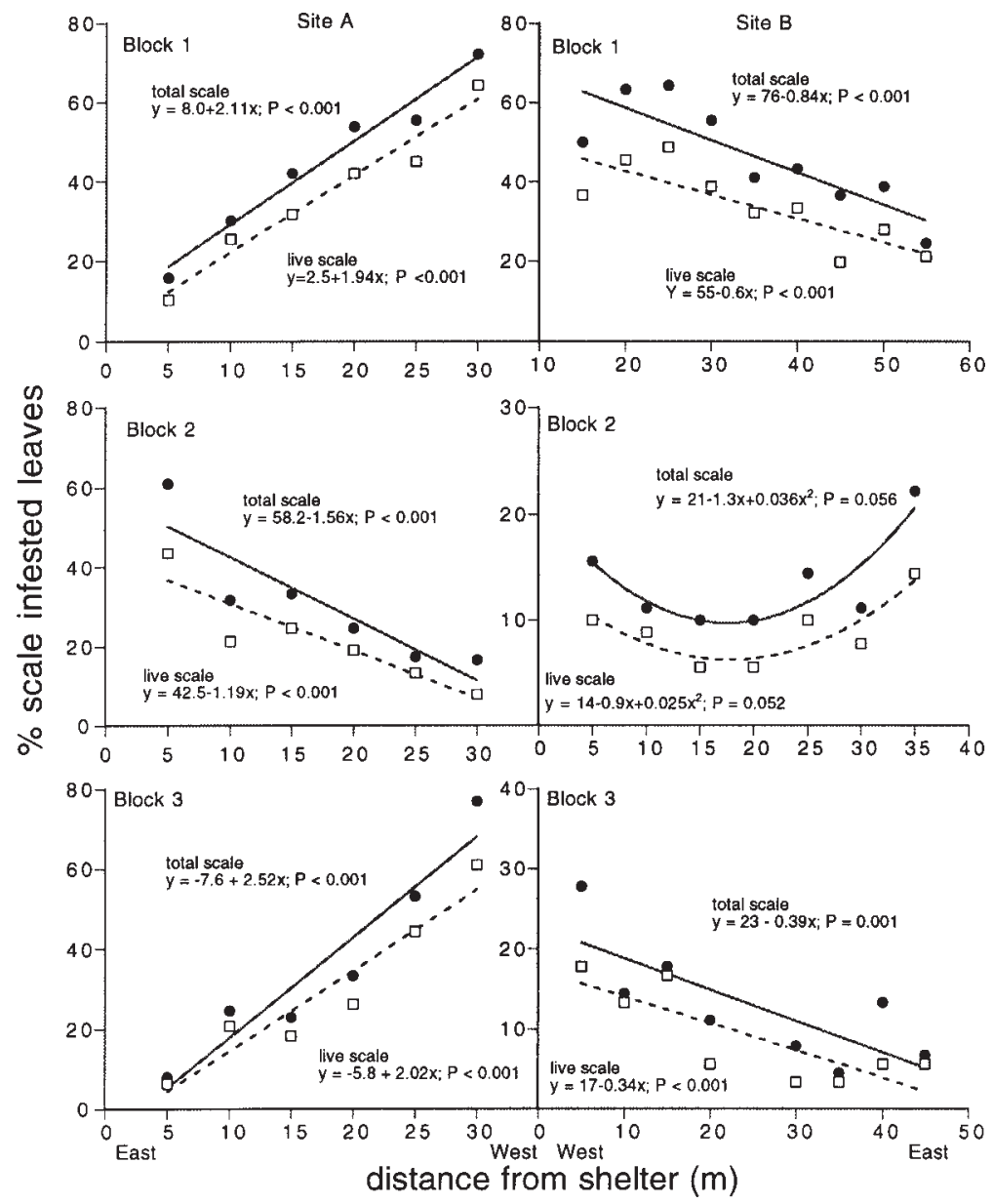

FIGURE 2: Total (live plus dead) and live scale distribution patterns across rows at three adjacent kiwifruit blocks at two sites. Regression curves giving the best fit of scale infestations for combined means from six sampling times.

host plants as sources of crawler invasion into kiwifruit blocks (Blanket al. 1990). It is of interest to determine the impact of prevailing winds and shelter on scale distribution at these sites. Bamboo is considered to be free of scale. The willow variety can harbour the occasional scale, however we consider it is a relatively minor source of crawlers compared to taraire.

Scale distribution patterns at Site B were consistent with crawlers being carried by the prevailing westerly quarter winds (approximately $53 \%$ of wind frequency) from the adjacent taraire trees across Block 1 and over the first shelter-belt to be deposited on the windward side of the second shelter-belt. Wind turbulence may be responsible for the similar high proportion of scale found in the lee of the second shelter-belt compared to the windward side of Block 3. 
There are several possible explanations for the scale patterns found at Site A. One scenario assumes that scale crawlers are carried by easterly quarter winds $(34 \%$ frequency) from the nearby taraire trees. The relatively tall shelter-belts may have reduced the proportion of crawlers deposited on the leeward side of the shelter so that the highest numbers occurred on the west side of Blocks 1 and 3. The different pattern in Block 2 may be caused by wind turbulence, caused by the tall taraire trees, occurring at Block 2 causing crawlers to be dumped against the leeward side of shelter. Another scenario assumes that crawlers are mainly carried by the prevailing westerly winds and that the major source of crawlers was derived from taraire trees on a hill overlooking the orchard approximately $0.5 \mathrm{~km}$ away.

In the simplest situation where a kiwifruit block was immediately adjacent to a major scale source, without any shelter in between and downwind from the prevailing wind (Site A, Block 1), scale infestations can be well described by a linear decline as row distance from the scale source increases. However, scale distributions were more complex where shelter-belts intervened between the scale source and the kiwifruit block. In some situations maximum scale abundance may occur in the exposed windward parts of the block whilst in others highest numbers were found in the leeward row. These contradictory findings may be explained by the effects of prevailing winds and turbulence.

Although scale distribution patterns are difficult to predict, the evidence that they are relatively consistent between sampling occasions, suggests that patterns are likely to remain similar between seasons. If this is so, there may be advantages to growers in determining scale distributions on selected blocks and in particular those with a high risk of scale attack. This might then offer the advantages of stratified sampling to improve spray control decisions. Unfortunately, the scale infestation data collected using the Kiwigreen sampling procedures were unable to describe scale distribution. This can be attributed to a combination of inadequate sample size and because every row was not sampled. This study has developed procedures for quantifying scale distribution patterns that have been successfully determined at two sites with high scale infestations. We now need to determine if these distribution patterns are representative of other kiwifruit blocks.

\section{ACKNOWLEDGEMENTS}

Our thanks to Hanley Hutchinson, Dave McNaughton of Huanui Orchard; Bob and Greg Herman of Darligen Orchards for allowing us to use their orchard blocks and to Jean Kelly, Brya Tapper and Stacey Townsend of HortResearch for carrying out the leaf assessments. This work was supported by the Foundation for Research Science and Technology and the New Zealand Kiwifruit Marketing Board.

\section{REFERENCES}

Berry, J.A., Morales, C.F., Hill, M.G., Loforth, B.J. and Allan, D.J., 1989. The incidence of three diaspidid scales on kiwifruit in New Zealand. Proc. 42nd N.Z. Weed and Pest Control Conf: 182-186.

Blank, R.H., Olson, M.H. and Lo, P.L., 1990. Armoured scale (Hemiptera: Diaspididae) aerial invasion into kiwifruit orchards from adjacent host plants. N.Z. J. Crop Hort. Sci 18: 81-87.

Lo, P.L. and Blank, R.H., 1989. A survey of armoured scale species (Hemiptera: Diaspididae) in Kiwifruit orchards. N.Z. Entomol. 12: 1-14.

Southwood, T.R.E., 1978. Ecological Methods. Chapman and Hall, London, 524 pp.

Steven, D., 1990. Entomology and kiwifruit. Pp 363-412. In: Kiwifruit: Science and management. I.J. Warrington and G.C. Weston(Eds.) N.Z. Soc. Hort. Sc., Auckland. 